\title{
PENGARUH VARIASI KOMPOSISI SILICA FUME TERHADAP KUAT LEKAT BETON MUTU TINGGI MEMADAT MANDIRI
}

\author{
Wibowo $^{1)}$, Sunarmasto ${ }^{2)}$, Delvi Maulana ${ }^{3)}$ \\ [1], [2] Pengajar Program Studi Teknik Sipil Fakultas Teknik Universitas Sebelas Maret \\ [3] Mahasiswa Program Studi Teknik Sipil Fakultas Teknik Universitas Sebelas Maret \\ Jl. Ir. Sutami 36 A, Kentingan Surakarta 57126. Telp (0271)647069. Fax 662118 \\ Email: maulanadelvi@gmail.com
}

\begin{abstract}
Development of Construction Industry encourages new innovations. One of innovations is high strength self-compacting concrete (HSSCC). This type of concrete has a high compressive strength and can compact without a vibrator. The Bond Strength is one of the most important properties in reinforced concrete structure. The loosing of bond strength cause failure in reinforced concrete structure. In this study silica fume used as a cement substitution and filler to improve the quality of concrete. The method used in this study was experimental and the parameters studied were the characteristics of fresh self-compacting concrete and the bond strength. The specimens used are cuboid in dimensions of $15 \mathrm{~cm}$ $\times 15 \mathrm{~cm} \times 15 \mathrm{~cm}$ with embedded $13 \mathrm{~mm}$ deformed bar. Based on the research, silica fume increases the strength of the concrete at 28 days. At 9,03\% content of silica fume attaches to the maximum point. The bond strength increases along with the improvement of concrete quality. The addition of silica fume decreases the workability and the concrete mixture becomes viscous, the substitution of cement with $8 \%$ silica fume meets the overall requirements of self-compacting concrete based on EFNARC.
\end{abstract}

Keywords $\quad$ : high strength self-compacting concrete, silica fume, bond strength, workability

\section{ABSTRAK}

Perkembangan dunia konstruksi melahirkan inovasi beton mutu tinggi memadat mandiri. Beton ini memiliki kuat tekan tinggi dan dapat memadat tanpa bantuan penggetar. Kuat lekat beton merupakan salah satu sifat penting dalam struktur beton bertulang. Kehilangan kekuatan lekat beton dapat menyebabkan keruntuhan total dalam struktur beton bertulang. Silica fume dalam penelitian ini digunakan sebagai substitusi semen dan material pengisi untuk meningkatkan mutu beton. Metode yang digunakan dalam penelitian ini adalah eksperimental dan parameter yang dikaji adalah karakteristik beton segar beton memadat mandiri dan kuat lekat beton. Benda uji yang digunakan berbentuk kubus dimensi $15 \mathrm{~cm} \times 15 \mathrm{~cm} \times 15 \mathrm{~cm}$ dengan tulangan tertanam baja tulangan berprofil ulir berdiameter $13 \mathrm{~mm}$. Berdasarkan penelitian, silica fume meningkatkan kuat lekat beton pada umur 28 hari. Pada kadar silica fume $9 \%$ kuat lekat mencapai titik maksimum. Peningkatan kuat lekat beton seiring dengan peningkatan mutu beton. Penambahan silica fume menurunkan workabilitas dan campuran beton menjadi kental, substitusi semen dengan silica fume kadar $8 \%$ memenuhi keseluruhan syarat beton memadat mandiri berdasarkan EFNARC.

Kata Kunci : beton mutu tinggi memadat mandiri, silica fume, kuat lekat, workabilitas

\section{PENDAHULUAN}

High Strength Self-Compacting Concrete (HSSCC) merupakan salah satu inovasi dalam dunia konstruksi yang memberikan solusi terkait masalah pengecoran pada struktur beton bertulang. Beton ini memiliki tingkat kecairan (fluidity) tinggi sehingga mampu mengalir dan mencapai kepadatan sendiri tanpa mengalami pemisahan air dengan semen dari adukan (bleeding) maupun pemisahan agregat dari adukan (segregasi). Penggunaan bahan tambah/bahan pengganti campuran beton dari material pozzolan seperti silica fume mampu memberikan peningkatan mutu beton. Ukuran partikel silica fume yang sangat kecil dapat mengisi rongga-rongga beton sehingga kepadatan beton meningkat.

Salah satu sifat penting dari beton keras dalam struktur beton bertulang adalah kuat lekat antara beton dan baja tulangannya. Kuat lekat beton adalah kombinasi dari adhesi, gesekan, dan dukungan dari baja tulangan. Kehilangan kekuatan lekatan beton dengan tulangannya menyebabkan keruntuhan total pada struktur. Peningkatan kuat lekat beton dapat dilakukan seperti meningkatkan ITZ (Interfacial Transition Zone) antar partikel penyusun beton dan baja tulangannya. 


\section{DASAR TEORI}

Menurut (SNI 03-6468-2000), beton mutu tinggi (high strength concrete) didefinisikan sebagai beton yang mempunyai kuat tekan yang disyaratkan lebih besar sama dengan 41,4 MPa.

Self-compacting concrete (SCC) adalah beton inovatif yang tidak memerlukan getaran untuk penempatan dan pemadatan. SCC mampu mengalir dengan beratnya sendiri, benar-benar mengisi bekisting dan mencapai pemadatan penuh, bahkan di hadapan kondisi penulangan yang padat. Daya tahan dan ketahanan segregasi dari SCC memastikan tingkat homogenitas yang tinggi, rongga beton minimal dan kekuatan beton yang seragam, memberikan potensi untuk tingkat akhir dan daya tahan yang lebih tinggi terhadap struktur (The European Project Group, 2005).

High Strength Self-compacting Concrete (HSSCC) adalah hasil pengembangan dan perbaikan sifat beton yang menggabungkan dua sifat beton yaitu sifat beton keras bermutu tinggi dan sifat beton segar yang mampu memadat mandiri. Beton ini mampu menjadi solusi atas permasalahan yang timbul akibat kemajuan dunia konstruksi khususnya pada struktur bangunan tinggi.

Reaksi kimia yang terjadi pada beton normal yaitu hidrasi $\mathrm{C}_{3} \mathrm{~S}$ dan $\mathrm{C}_{2} \mathrm{~S}$ adalah sebagai berikut:

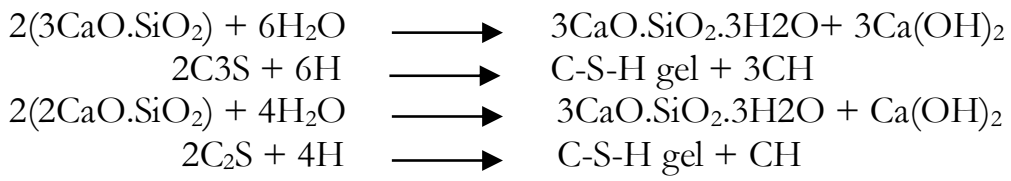

Kandungan silika dalam silica fume akan mengikat dan bereaksi dengan kelebihan $\mathrm{CH}$ hasil hidrasi dan membentuk CSH (Calcium Silicat Hydarate) yang merupakan senyawa utama yang meningkatkan sifat mekanik beton, memperbaiki struktur pori beton menjadi lebih padat sehingga mutu beton lebih tinggi. Reaksi kimia $\mathrm{Ca}(\mathrm{OH})_{2}$ dengan $\mathrm{SiO}_{2}$ adalah sebagai berikut:

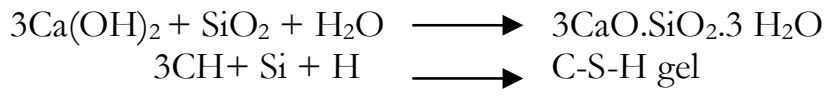

Komposisi jumlah kadar silica fume yang disubstitusikan dengan semen harus tepat untuk menghasilkan perbaikan sifat beton yang paling optimal. (Serag, dkk, 2017) mempelajari pengaruh penambahan silica fume hingga 4,5\% dari berat semen pada pola keruntuhan kuat lekat beton. Hasil penelitian menunjukkan bahwa dengan penambahan 3\% silica fume sebagai pengganti sebagian semen, kuat tekan, kuat tarik belah dan kuat lekat meningkat masing-masing 43,5\%, 12\% dan $38,5 \%$ dibandingkan dengan beton normal.

\section{METODE PENELITIAN}

\section{Bahan dan Proporsi Campuran}

Bahan bahan yang digunakan untuk membuat campuran HSSCC antara lain :

1. Powder

a. Semen: semen yang digunakan adalah Ordinary Portland Cement Indocement.

b. Silica fume hasil produksi PT. Sika Indonesia sebagai substitusi $8-11 \%$ semen.

2. Agregat kasar

Ukuran butir maksimum yang digunakan adalah $19 \mathrm{~mm}$. Ukuran butir maksimum untuk beton normal adalah $35 \mathrm{~mm}$. Specific grafity sebesar $2,67 \mathrm{t} / \mathrm{m}^{3}$.

3. Agregat halus

Ukuran butir yang digunakan adalah 4,75 mm. Specific grafity sebesar 2,57 t/ $\mathrm{m}^{3}$.

4. Air

Faktor air semen yang digunakan untuk HSSCC adalah sebesar 0,3.

5. Bahan campur (admixture) 
Bahan campur (admixture) yang digunakan adalah superplasticizer dengan merk MasterGlenium SKY 8851.

\section{Rumus yang Digunakan}

$\sigma=\frac{P}{\pi \cdot d b \cdot l d}$

dengan :

$\sigma \quad=$ kuat lekat beton $(\mathrm{MPa})$

$\mathrm{P} \quad \quad=$ gaya tarik maksimum $(\mathrm{N})$

$\mathrm{db} \quad=$ diameter tulangan $(\mathrm{mm})$

ld $\quad=$ panjang tulangan tertanam $(\mathrm{mm})$

Tabel 1. Proporsi Campuran HSSCC setiap $1 \mathrm{~m}^{3}$

\begin{tabular}{ccccccc}
\hline Kode & Semen $(\mathrm{kg})$ & Silica fume $(\mathrm{kg})$ & Fine Agg $(\mathrm{kg})$ & Coarse Agg $(\mathrm{kg})$ & Air $(\mathrm{lt})$ & Superplacticizer $(\mathrm{lt})$ \\
\hline HSSCC.SF.0 $\%$ & 550 & 0 & 916,32 & 801,25 & 165 & 4,13 \\
\hline HSSCC.SF.8\% & 506 & 44 & 902,17 & 801,25 & 165 & 4,13 \\
\hline HSSCC.SF.9\% & 500,5 & 49,5 & 900,40 & 801,25 & 165 & 4,13 \\
\hline HSSCC.SF.10\% & 495 & 55 & 898,64 & 801,25 & 165 & 4,13 \\
\hline HSSCC.SF.11\% & 489,5 & 60,5 & 896,87 & 801,25 & 165 & 4,13 \\
\hline
\end{tabular}

Pembuatan rancang campur menggunakan standar EFNARC.

\section{Pengujian Kuat Lekat}

Benda uji yang dibuat berupa kubus ukuran $15 \mathrm{~cm}$ x $15 \mathrm{~cm} \times 15 \mathrm{~cm}$ sebanyak 20 buah. Panjang tulangan tertanam dibuat seragam sebesar $15 \mathrm{~cm}$ dengan baja tulangan berprofil ulir diameter $13 \mathrm{~mm}$ seperti pada Gambar. 1.
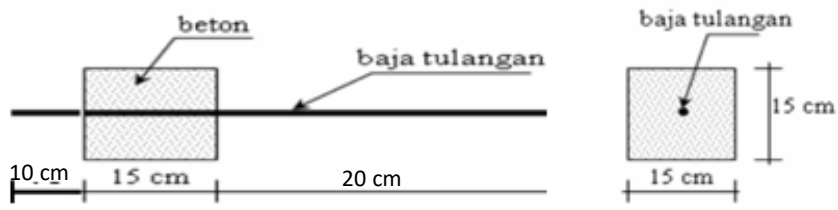

Gambar. 1 Detail Benda Uji

Pengujian kuat lekat beton dilakukan saat umur beton mencapai 28 hari. Pengujian dilakukan dengan UTM (Universal Testing Machine). Dial Indikator dipasang pada salah satu ujung tulangan untuk mengetahui terjadinya slip sebesar 0,25 $\mathrm{mm}$ saat gaya tarik diberikan pada ujung tulangan lainnya. Detail pengaturan alat uji ditunjukkan pada Gambar. 2.

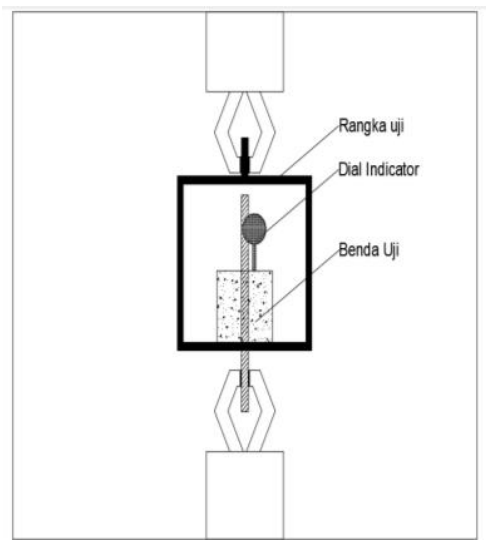


Gambar. 2 Detail Pengaturan Alat Uji

HASIL DAN PEMBAHASAN

Pengujian Fresh Concrete

Pengujian beton segar dilakukan sesuai aturan EFNARC "Specification and Guidelines for Self - Compacting Concrete". Pengujian yang dilakukan berupa Flow Table Test, L-Box test, V-Funnel test.

Tabel 2 Hasil Pengujian Flow Table Test HSSCC

\begin{tabular}{ccccc}
\hline \multirow{2}{*}{ Kode } & \multicolumn{3}{c}{ Diameter } & Waktu \\
\cline { 2 - 5 } & $\begin{array}{c}\mathrm{d} 1 \\
(\mathrm{~mm})\end{array}$ & $\begin{array}{c}\mathrm{d} 2 \\
(\mathrm{~mm})\end{array}$ & $\begin{array}{c}\mathrm{d}_{\text {rata-rata }} \\
(\mathrm{mm})\end{array}$ & $\begin{array}{c}\mathrm{t}_{50} \\
(\mathrm{dt})\end{array}$ \\
\hline HSSCC.SF.0 $\%$ & 660 & 670 & 665 & 3,1 \\
\hline HSSCC.SF.8\% & 700 & 710 & 705 & 2,1 \\
\hline HSSCC.SF.9\% & 710 & 650 & 680 & 3,6 \\
\hline HSSCC.SF.10\% & 690 & 630 & 660 & 4,5 \\
\hline HSSCC.SF.11\% & 660 & 650 & 655 & 6,2 \\
\hline
\end{tabular}

Pada Tabel 2 hasil pengujian Flow Table hanya kadar 11\% yang tidak memenuhi standar persyaratan beton EFNARC dimana disyaratkan diameter yang harus dicapai adalah $650 \mathrm{~mm}-800 \mathrm{~mm}$ dalam waktu 2-5 detik. Hasil ini menunjukkan beton variasi kadar 8\%,9\% dan 10\% memiliki kemampuan filling ability yang baik.

Tabel 3 Hasil Pengujian L-Box Test HSSCC

\begin{tabular}{cccccc}
\hline Kode & $\begin{array}{c}\mathrm{h}_{1} \\
(\mathrm{~mm})\end{array}$ & $\begin{array}{c}\mathrm{h}_{2} \\
(\mathrm{~mm})\end{array}$ & $\mathrm{h}_{2} / \mathrm{h}_{1}$ & $\begin{array}{c}\text { Syarat } \\
\left(\mathrm{h}_{2} / \mathrm{h}_{1}\right)\end{array}$ & Keterangan \\
\hline HSSCC.SF.0 $\%$ & 70 & 70 & 1 & $0,8-1,0$ & Memenuhi \\
\hline HSSCC.SF.8 $\%$ & 80 & 70 & 0,88 & $0,8-1,0$ & Memenuhi \\
\hline HSSCC.SF.9\% & 85 & 70 & 0.82 & $0,8-1,0$ & Memenuhi \\
\hline HSSCC.SF.10\% & 95 & 60 & 0,63 & $0,8-1,0$ & Tidak Memenuhi \\
\hline HSSCC.SF.11\% & 100 & 55 & 0,55 & $0,8-1,0$ & Tidak Memenuhi \\
\hline
\end{tabular}

Pada Tabel 3 hasil pengujian L-Box variasi kadar 10\% dan 11\% tidak memenuhi standar persyaratan beton EFNARC dimana disyaratkan $\mathrm{h}_{2} / \mathrm{h}_{1}$ harus memiliki nilai $0,8-1,0$. Hasil ini menunjukkan beton dengan penambahan kadar $8 \%$, dan $9 \%$ memiliki kemampuan passing ability yang baik.

Tabel 4 Hasil Pengujian V-Funnel Test HSSCC

\begin{tabular}{cccccc}
\hline \multirow{2}{*}{ Kode } & \multicolumn{3}{c}{ V-Funnel Test } & \multicolumn{2}{c}{ V-Funnel $T_{5 \text { minutes }}$} \\
\cline { 2 - 6 } & $\begin{array}{c}\mathrm{t} \\
\mathrm{ddt}\end{array}$ & $\begin{array}{c}\text { Syarat } \\
(\mathrm{t})\end{array}$ & Keterangan & $\begin{array}{c}\mathrm{t} \\
(\mathrm{dt})\end{array}$ & $\begin{array}{c}\Delta \mathrm{t} \\
(\mathrm{dt})\end{array}$ \\
\hline HSSCC.SF.0 $\%$ & 8,3 & $8-12 \mathrm{dt}$ & Memenuhi & 12,2 & 3,9 \\
\hline HSSCC.SF.8 $\%$ & 9,5 & $8-12 \mathrm{dt}$ & Memenuhi & 11,9 & 2,4 \\
\hline HSSCC.SF.9\% & 10,2 & $8-12 \mathrm{dt}$ & Memenuhi & 17,2 & 7 \\
\hline HSSCC.SF.10\% & 16,3 & $8-12 \mathrm{dt}$ & Tidak Memenuhi & 24,4 & 8,1 \\
\hline HSSCC.SF.11\% & 19,4 & $8-12 \mathrm{dt}$ & Tidak Memenuhi & 26 & 6,6 \\
\hline
\end{tabular}

Pada Tabel 4 hasil pengujian $V$-Funnelvariasi kadar 10\% dan 11\% tidak memenuhi standar persyaratan beton EFNARC dimana disyaratkan waktu yang harus ditempuh adalah $6-12$ detik. Dan pada pengujian $V$-Funnel $T_{5 \text { minutes }}$ dimana beton segar didiamkan selama 5 menit dan diuji kembali pada $V$-Funnel menunjukkan bahwa hanya beton dengan kadar $8 \%$ yang memenuhi standar EFNARC dan memiliki segregation resistance yang baik. 
Dari keseluruhan uji parameter SCC, hasil pengujian menunjukkan bahwa beton dengan penambahan kadar 8\% yang memiliki filling ability, passing ability dan segregation resistance yang baik.

\section{Hasil Pengujian Kuat Lekat Beton}

Pada saat benda uji berumur 28 hari dilakukan pengujian kuat lekat beton.

Tabel 5. Hasil Kuat Lekat Beton

\begin{tabular}{|c|c|c|c|c|c|}
\hline No & Nama Benda Uji & $\begin{array}{c}\text { Kode Benda } \\
\text { Uji }\end{array}$ & $\begin{array}{l}\text { Gaya cabut } \\
(\mathrm{N})\end{array}$ & $\begin{array}{c}\text { Gaya cabut rata-rata } \\
(\mathrm{N})\end{array}$ & $\begin{array}{c}\text { Kuat Lekat rata-rata } \\
(\mathrm{MPa})\end{array}$ \\
\hline \multirow{3}{*}{1.} & \multirow{3}{*}{ Hsscc $-\mathrm{SF} 0 \%$} & $\mathrm{I}$ & 55750 & \multirow{3}{*}{56003} & \multirow{3}{*}{9,44} \\
\hline & & II & 57620 & & \\
\hline & & III & 54640 & & \\
\hline \multirow{3}{*}{2.} & \multirow{3}{*}{ Hsscc - SF 8\% } & $\mathrm{I}$ & 60680 & \multirow{3}{*}{57957} & \multirow{3}{*}{9,77} \\
\hline & & II & 59120 & & \\
\hline & & III & 54070 & & \\
\hline \multirow{3}{*}{3.} & \multirow{3}{*}{ Hsscc - SF 9\% } & I & 52620 & \multirow{3}{*}{58633} & \multirow{3}{*}{9,88} \\
\hline & & II & 67500 & & \\
\hline & & III & 55780 & & \\
\hline \multirow{3}{*}{4.} & \multirow{3}{*}{ Hsscc - SF 10\% } & $\mathrm{I}$ & 60070 & \multirow{3}{*}{58087} & \multirow{3}{*}{9,79} \\
\hline & & II & 60300 & & \\
\hline & & III & 53890 & & \\
\hline \multirow{3}{*}{5.} & \multirow{3}{*}{ Hsscc - SF 11\% } & I & 57710 & \multirow{3}{*}{55890} & \multirow{3}{*}{9,42} \\
\hline & & II & 55700 & & \\
\hline & & III & 54260 & & \\
\hline
\end{tabular}

Berdasarkan hasil pengujian kuat lekat beton pada Tabel 5 diatas terdapat peningkatan kekuatan lekat beton pada campuran dengan substitusi kadar silica fume $8 \%$ sebesar $0,33 \mathrm{MPa}$ dan mencapai puncaknya pada kadar silica fume $9 \%$ dengan peningkatan sebesar 0,44 MPa, kemudian kekuatan lekat beton menurun pada kadar silica fume 10\% sebesar 0,09 Mpa dan mencapai titik terendah (lebih kecil dari beton normal) pada kadar silica fume 11\%. Variasi kadar silica fume optimal dalam peningkatan kuat lekat adalah kadar 9,03\% silica fume.

Tabel 6. Hasil Kuat Tekan Beton

\begin{tabular}{cccc}
\hline Kode & $\begin{array}{c}\text { Pmax } \\
(\mathrm{kN})\end{array}$ & $\begin{array}{c}\text { Kuat Tekan } \\
(\mathrm{MPa})\end{array}$ & $\begin{array}{c}\Delta \\
(\%)\end{array}$ \\
\hline Hsscc $-\mathrm{SF} \mathrm{0 \%}$ & 190,04 & 43,02 & 31,76 \\
\hline Hsscc $-\mathrm{SF} 8 \%$ & 250,40 & 56,68 & 57,27 \\
\hline Hsscc $-\mathrm{SF} 9 \%$ & 298,88 & 67,65 & 47,41 \\
\hline Hsscc $-\mathrm{SF} \mathrm{10 \%}$ & 280,14 & 63,41 & 25,31 \\
\hline Hsscc $-\mathrm{SF} \mathrm{11 \%}$ & 238,15 & 53,91 & 2 \\
\hline
\end{tabular}

Untuk melihat pengaruh mutu beton terhadap kuat lekat, hasil pengujian kuat tekan beton merujuk pada penelitian yang dilakukan oleh Wahyu Satrio,2018. Berdasarkan tabel hasil pengujian diatas didapat bahwa ada pengaruh mutu beton terhadap kuat lekat beton dengan tulangannya. Semakin tinggi kuat tekan beton maka kuat lekat akan semakin tinggi. Hal tersebut terjadi karena struktur beton akan semakin padat dan friksi antara partikel-partikel keras dalam 
beton dengan permukaan ulir tulangan akan semakin besar sehingga interlock dan lekatan keduanya akan semakin besar pula.

\section{SIMPULAN}

Dari hasil pembahasan diatas dapat diambil beberapa kesimpulan sebagai berikut:

1. Berdasarkan hasil pengujian parameter SCC pada beton segar, substitusi semen dengan kadar silica fume sebesar $8 \%$ memberikan hasil yang baik dalam karakteristik beton SCC. Semakin tinggi kadar silica fume yang disubstitusikan maka kemampuan mengalir beton akan semakin berkurang karena beton akan semakin kental (viscous).

2. Berdasarkan hasil uji kuat lekat beton, kadar silica fume sebesar 9,03\% adalah kadar optimum dan menghasilkan kuat lekat beton paling tinggi.

3. Mutu beton berpengaruh terhadap kuat lekat beton dan tulangannya. Semakin tinggi mutu beton maka semakin tinggi pula kuat lekat antara beton dan tulangannya.

\section{REKOMENDASI}

1. Untuk mencapai tujuan penelitian yang diharapkan, penelitian selanjutnya disarankan untuk menambah jumlah benda uji sehingga data yang diperoleh lebih akurat.

2. Perlu diadakan penelitian lanjutan untuk mengetahui kuat lekat yang terjadi menggunakan diameter dan panjang tulangan tertanam yang berbeda.

3. Perlu meningkatkan metode uji kuat lekat yang lebih efektif menggunakan indikator yang lebih akurat.

\section{UCAPAN TERIMA KASIH}

Ucapan terima kasih penulis sampaikan kepada Bapak Wibowo, S.T., DEA. dan Bapak Ir. Sunarmasto, M.T. selaku pembimbing yang dengan penuh kesabaran telah memberi koreksi dan arahan sehingga menyempurnakan penyusunan.

\section{REFERENSI}

Anonim. 1971. "Peraturan Beton Bertulang Indonesia". Bandung: Departemen Pekerjaan Umum.

Anonim. 1991. Standard Test Method for Comparing Concrete on the Basis of the Bond Developed with Reinforcing Steel. ASTM C234-91a. West Conshohocken, PA, USA: ASTM International

Anonim. 2005. The European Guidelines for Self-Compacting Concrete. The European Guidelines for Self Compacting Concrete, (May), 63.

Anonim. 2006. Guide for the Use of Silica Fume in Concrete. ACI 234R-06, 96(Reapproved), 0-64.

Anonim. 2013. Persyaratan beton struktural untuk bangunan gedung. Standar Nasional Indonesia, 265.

Sunarmasto. (2007). Tegangan Lekat Baja Tulangan (Polos Dan Ulir) Pada Beton. Gema Teknik, 10(2), 76-82.

Tjokrodimulyo, Kardiyono. 1995. “Teknologi Beton”. Yogyakarta: Biro Penerbit Teknik Sipil Universitas Gajah Mada.

Xu, Y., \& Chung, D. D. L. (2000). Improving silica fume cement by using silane. Cement and Concrete Research, 30(8), 1305-1311.

Zhu, W., Sonebi, M., \& Bartos, P. J. M. (2004). Bond and interfacial properties of reinforcement in self-compacting concrete Bond, (February 2014). 